\title{
Features of the state pricing system in construction in the Russian Federation
}

\author{
Oksana Ivanova $^{1 *}$, Daria Ivanova ${ }^{2}$, and Sergey Sukhinin ${ }^{1}$ \\ ${ }^{1}$ Don State Technical University, 344003, Rostov-on-Don, Russia \\ ${ }^{2}$ Rostov State University of Economics, 344002, Rostov-on-Don, Russia
}

\begin{abstract}
Pricing in construction is the process of calculating the price of construction objects based on the estimated cost of construction materials and construction and installation work. It is carried out under the control and with the direct participation of specialized government bodies. Improvement of the public administration system in construction is transforming the approaches and methods of state pricing in the industry. This is due to the desire to more accurately and objectively take into account all the costs incurred in the course of construction and installation work, which change primarily under the influence of inflationary processes and the rising cost of building materials. Each erected building or structure in construction has its own individual price. The price for a construction object should not be overstated, but at the same time, it must comply with the established construction standards. In the system of state pricing in construction, two main methods of calculating the estimated cost of a construction object are used - base-index and resource. The first method is based on the use of unit prices developed taking into account the price level in the base period and their adjustment using the estimated cost indices. The resource calculation method is based on current prices for structural materials and construction work. The study provides a comparative assessment of the two methods, determines their effectiveness, identifies the problems of state pricing in construction in the Russian Federation. To achieve transparency in determining the construction cost, it was decided to switch to the resource method of drawing up estimate documentation as more objective, despite the significant laboriousness of calculations.
\end{abstract}

\section{Introduction}

The ongoing changes in the national economy, the transformation of society needs and the rational use of resources and financial resources necessary for production necessitate the improvement of various spheres and sectors of the economy, including construction. Construction is developing in two sectors - private and public. The role of the state in this case is expressed not only in equity participation in the assets of construction companies, but also in the direct participation of government bodies in the development of projects and the construction of facilities important for the national economy.

\footnotetext{
*Corresponding author: oeiva25@yandex.ru
} 
One of the tasks of state participation in the construction industry is objective pricing, taking into account the emergence of new approaches, methods, regulatory documents and requirements for accounting for the cost of construction materials and work. In the context of the market relations' development, the prices for building materials are formed not only under the influence of factors related to supply and demand, but also due to other externalities [1]. Therefore, the state is called upon to play a significant role in the pricing system in construction, pursuing through specialized bodies an adequate pricing policy based on price accounting and estimated rationing of building materials and construction and installation works.

In the course of construction industry state regulation, the problem of construction materials' rational use allocated for construction activities comes to the fore. This is due to the fact that the state finances mainly the construction of social facilities or significant for the use of large objects of housing and communal services and transport infrastructure. Therefore, the efficiency of the entire construction process depends on the purposeful use of building materials purchased from the state budget. An important role in this is played by the state pricing system organization, which is aimed at substantiated and objective calculation of prices for building materials and determining the cost of construction and installation work required for the construction of buildings and structures. This article is devoted to the consideration of the state pricing system modern mechanism features in construction on the basis of adequate calculation and estimated rationing of essential construction materials and construction work.

The problems of pricing and estimated rationing in construction related to the calculation of prices for building materials and the following works are outlined in scientific publications of such scientists as R. Stasiak-Betlejewska, M. Potkanyb [2], R. Antunes, V. Gonzalez [3], O.J. Klakegg, S. Lichtenberg [4], A.F. Remon, Y.M. Aboelmagd [5] and others. Information on the issues of state regulation in the construction industry of the Russian Federation was investigated in their works by M.V. Gogitidze, O.I. Guzenko, A.G. Sapozhnikova [6], I.Y. Zilberova [7, 8], I.V. Novoselova, [9], N.A. Osadchaya [10] and others. These works served as the theoretical basis for our research.

The purpose of this article is to analyze modern approaches and methods of state pricing in the construction industry of the Russian Federation. The objectives of the study were the following:

- identifying the essence and specifics of the state pricing system in construction;

- comparative characteristics of approaches and methods of state pricing in construction;

- identification of problems and ways to improve the mechanism for calculating the cost of construction products in the public sector of the construction industry of the Russian Federation.

\section{Results}

Construction is one of the few economy sectors where the degree of government regulation remains quite high. This is due to the fact that the construction of important social and economic facilities is carried out mainly with the attraction of funds from the state budget, and only a small share of investments is made by private investors.

Pricing, as a set of methods, principles, rules for determining and setting prices for goods and services with the aim of selling them and ensuring competitiveness, takes place in all sectors and spheres of economic activity. Pricing in construction has its own specifics associated with the complexity of the construction process, the duration of the production cycle, the use of various building materials during it, and the involvement of subcontractors for construction work. All this necessitates significant investments in the implementation of 
construction, and, consequently, their detailed calculation at the preparatory stage. In this regard, pricing in construction consists in setting the final price for structural materials and construction and installation work by developing an appropriate estimate, taking into account the principles of rationality and economy of resource use.

The main emphasis of the state pricing system in construction is expressed in the regulation of the distribution of budgetary funds. At the same time, the function of government bodies in the pricing system in construction is related to the regulation of prices for construction materials and construction work and control over their observance by developers. It is the institutes of state and management of the construction industry - from the Federal Ministry of Construction, Housing and Utilities of the Russian Federation and ending with the department or administration of the city or district administrations construction, that act as participants in the organization of the state system of pricing in construction. They participate in the implementation of the state pricing policy in construction, which is based on the calculation of objectively necessary costs for construction materials and construction and installation work according to certain calculation rules.

The basis for state pricing in the construction of the Russian Federation is the methodological documents developed and approved by the Ministry of Construction, Housing and Communal Services of the Russian Federation. They contain various techniques and methods, special instructions, and recommendations for determining the cost of a construction object being erected and carrying out the construction and installation works.

In the state regulation of prices for construction products, methods of direct and indirect influence are used. Direct (administrative) impact is the establishment of a certain order of pricing in construction. This method includes the establishment of base prices to determine the cost of construction materials and construction and installation work and their adjustment using the marginal coefficients of change in base prices. Direct regulation can be viewed as a tough targeted government intervention in the pricing process in construction.

Methods of indirect (economic) regulation are manifested in the impact not on the prices themselves, but on the factors affecting pricing and having a macroeconomic nature. By these measures, the state seeks to promote a more even and slow increase in prices for construction materials and construction and installation work. These methods include government procurement of building materials, examination of construction projects, tax incentives and subsidies to construction organizations, government investment in construction $[11,12]$.

In the practice of managing the construction industry, various methods of determining prices are used, depending on the method of their state regulation, industry characteristics, contract terms and other factors. Estimated prices are formed in accordance with the industry specifics in construction. The estimated price is the calculated cost of construction, determined during the design, taking into account the technological, volumetric planning and structural solutions of the object.

There are two main methods for calculating the estimated price in the Russian Federation:

1. Resource method. It is a summation of the elements of costs for construction materials and ongoing construction and installation work in the current prices of the construction project. As the calculation elements of the estimated price by this method, the costs of labor resources, construction machines, material resources, taken into account in the collections of state elementary estimate norms, are determined. At the same time, the construction estimate is formed on the basis of reference books of state elementary estimate standards, taking into account the planned volume of work and the use, if necessary, of correction factors that take into account the conditions of work (for example, a cold climate or high-rise construction and installation work).

The advantages of the resource method of drawing up the estimate documentation is that it makes it possible to determine the final cost of construction products at the current price level 
with a sufficiently high accuracy. Despite this, there are a number of disadvantages, most of which are associated with the laboriousness of the calculation work and the large volume of estimate documentation being prepared. Therefore, the preparation of estimate documentation using the resource method, especially for large construction projects, is possible only with a specialized computer program. It is also very problematic to draw up a full estimate, since the cost of each specific resource is constantly changing.

2. The base-index method is based on the establishment of an estimated price by means of unit prices for structural materials and construction and installation works and price indices that take into account their change in comparison with the base calculation period. Unit prices are presented in collections by type of work, which form federal and territorial estimates as well as regulatory frameworks. They are the documentary basis for calculating cost indicators by multiplying the estimated rates of itemized prices by their base prices. A distinctive feature of this method of budgeting is its focus on the approximation of the construction cost determination to the average value for the region.

\section{Discussion}

At present, the basic-index method remains the main method of drawing up estimate documentation during the construction of objects sold at the expense of budgetary funds. Unit prices for construction materials and construction and installation works, according to this method, are taken into account in 2000 basic prices with subsequent indexation to the current price level based on the estimated cost change indices.

In connection with the outdated estimate and regulatory framework, attempts have been made to change or supplement it. So, the changes were made in 2010, 2014, 2017. However, they did not fundamentally change the way of determining the estimated cost and, in fact, the price standards approved more than 20 years ago are currently used. In this regard, there is an acute question of the need to develop standards for new technologies at present, to regularly update and supplement collections of elementary estimate standards and unit prices. To eliminate these shortcomings and breakdown, the authors propose to use the calculation of the estimated cost by the resource method, as more adequate in relation to the inflation rate and the real costs of construction organizations involved in the work. The calculation of the estimated cost by the resource method is carried out by calculating the cost elements necessary for the design solutions' implementation at the current price level.

To compare the resource and base-index methods of state pricing in construction, we will draw up the estimate documentation developed for each of them. As an example, let us take the position of the construction estimate "Execution of earthworks and installation of foundations" (Table 1).

Table 1. Calculation of the estimated cost of construction work by various methods

\begin{tabular}{|l|c|c|c|}
\hline \multirow{2}{*}{$\begin{array}{c}\text { Naming of } \\
\text { expenditures }\end{array}$} & \multicolumn{2}{|c|}{ Estimated cost of work, rubles } & \multirow{2}{*}{ Deviation, \% } \\
\cline { 2 - 3 } & base-index method & $\begin{array}{c}\text { resource } \\
\text { method }\end{array}$ & \\
\hline Excavation & 2352783 & 2940979 & 20,0 \\
\hline $\begin{array}{l}\text { Construction of } \\
\text { foundations }\end{array}$ & 2401003 & 2824709 & 15,0 \\
\hline Total & 4753786 & 5765688 & 17,6 \\
\hline
\end{tabular}

Calculated by the authors based on the research results

According to the calculation results, we observe a discrepancy between the estimated cost 
of construction work, calculated by the resource method compared to the base-index method, within $15-20 \%$. This is primarily due to the obsolescence of basic prices due to inflation. So, for example, the actual cost of B15 grade concrete according to the monitoring of prices for building resources in the Rostov region in the $2^{\text {nd }}$ quarter of 2020 was 1949 rubles per $\mathrm{m}^{3}$, on the floor, the cost in the territorial collection of unit rates (with recalculation of indices) was equal to 2338 rubles for $\mathrm{m}^{3}$, which gave the revealed difference in the calculation of work on the foundation construction in the amount of $20 \%$.

Thus, according to the comparative analysis results, we observe a greater objectivity of the resource method in calculating the cost of construction and installation work and structural materials. Despite its great labor intensity, the estimate calculation by this method makes it possible to take into account the real costs and make the estimate more adequate to the economic situation in the construction region.

\section{Conclusion}

The state pricing system is an important tool for determining the amount of the required capital investments in construction process. It is a multi-level, dynamic process that changes through the development of new legislative and legal documents regulating the procedure for determining the necessary material and financial resources for construction. In the process of calculating an adequate and rational cost of construction resources, the conflicting interests of all participants in the construction industry intersect. Therefore, it is necessary to use objective methods for calculating the estimated cost of construction materials and construction and installation work for the effective development of the industry.

Comparing the two methods for calculating the estimated cost of construction work and materials, the advantages of the resource method are obvious. However, the process of its implementation into practice of state pricing in construction comes down to the laboriousness of performing this calculation and checking it. Taking into account some features of performing the calculation by this method, one-step transition is not possible. In the Russian Federation, a state policy is being pursued of a gradual transition to the resource method of drawing up estimates. Its final commissioning is scheduled for 2022.

The state pricing system in construction is an important function of the entire public administration system. It makes it possible to regulate the construction industry by the approval of estimated standards and the introduction of methodological documents containing various techniques and methods, recommendations for determining the cost, consumable building materials and carrying out construction and installation works during the construction of a building facility. However, the realities of a market economy require a change in the nature of state pricing and a shift in the vector of its development from a managerial to a regulatory direction. This is due to the constant monitoring of the construction industry state as well as the construction work market, the transition from administrative and legal regulation of the construction sector based on regulatory instruments to more flexible financial mechanisms, including those associated with the transformation of methods for calculating the estimated cost of construction work and materials.

\section{References}

1. E. Mirgorodskaya, S. Sytnik, Terra 4-3, 100-104 (2012).

2. R. Stasiak-Betlejewska, M. Potkanyb, Procedia Econ. Finance 34, 35-42 (2015).

3. R. Antunes, V. Gonzalez, Buildings 5, 209-228 (2015).

4. O.J. Klakegg, S. Lichtenberg, Procedia Soc. Behav. Sci. 226, 176-183 (2016). 
5. A.F. Remon, Y.M. Aboelmagd, Alexandria Engineering Journal 58-1, 151-162 (2019).

6. M.V. Gogitidze, O.I. Guzenko, A.G. Sapozhnikova, MSF 931, 1214-19 (2018).

7. I.Y. Zilberova, V.D. Mailyan, I.V. Novoselova, IOP Conf. Ser.: Mater. Sci. Eng. 698, 055013 (2019).

8. I.Y. Zilberova, K.S. Petrov, N. A. F. A. Mohsen, IOP Conf. Ser.: Mater. Sci. Eng. 913, 042019 (2020).

9. E.O. Mirgorodskaya, I.V. Novoselova, V.Y. Steiner, MSF. 931, 1160-1164 (2018).

10. E.V. Puchkov, N.A. Osadchaya, A.D. Murzin, JARLE. 9, 615-624 (2018).

11. E.N. Sidorenko, V.A. Semiglazova, IOP Conf. Ser.: Mater. Sci. Eng. 913, 052012 (2020)

12. D.G. Ivanova, O.E. Ivanova, S.A. Sukhinin, IOP Conf. Ser.: Mater. Sci. Eng. 913, 052017 (2020). 